\title{
Analysis of the Evolution of Low carbon Independent Innovation
}

\author{
Tingfa Zhang \\ Research Department, Qilu Normal University, China \\ ztfsdu2011@163.com
}

Keywords: Low-carbon; Independent Innovation; Low-carbon economy; Green economy

\begin{abstract}
Under the ecological crisis, climate change threatens the survival and development of human beings, the total amount of industrial carbon emissions continues to increase, a serious threat to the harmonious development of man and nature, promote low-carbon economy and ecological civilization is imminent. Low-carbon independent innovation has become an inevitable choice for China to develop low-carbon economy, but also a powerful weapon for China to adjust its economic structure, cope with international competition and improve its comprehensive national strength. Independent innovation model as a way to improve the capacity of independent innovation experience, has become the key to achieving low-carbon independent innovation.
\end{abstract}

\section{Introduction}

With the development of the times, enterprises are increasingly concerned about the protection of intellectual property rights, independent innovation has become the only way to achieve leapfrog development. However, in today's climate warming has become the hottest topic in the world, governments actively advocate low-carbon economy, green economy era, so the development of low-carbon independent innovation will become the key to building an innovative country. Since Schumpeter opened innovative theory in 1912, scholars have studied this theory and its branches. With the global warming, the greenhouse effect is gradually exacerbated, low-carbon economy and low-carbon independent innovation by governments urgently put on the agenda, by many scholars of great concern, low-carbon independent innovation theory has been further developed and improved.

\section{The Connotation of Low - Carbon Independent Innovation}

Low-carbon independent innovation is based on innovation into the low-carbon areas of thinking, so that low-carbon industry development and ahead of international standards. Low-carbon independent innovation as a new concept, is still in the "connotation defined" development stage, mainly from independent innovation and low-carbon economy in two areas.

The Connotation of Independent Innovation. Independent innovation refers to the process of realizing the value of new products on the basis of unique core technologies with independent intellectual property rights. Independent innovation includes original innovation, integrated innovation and the introduction of digestion and absorption of innovation. The results of independent innovation, generally reflecte in the new scientific discovery and have independent intellectual property rights of technology, products, brands and so on.

Independent innovation ability is the decisive factor of comprehensive national strength competition and bones to support a country's rise and development and a country's long-term core competitiveness of the foundation, but also the core competitiveness of enterprises to cultivate the key link. For enterprises, independent innovation capability is the ability to independently integrate and apply various technical knowledge and gain competitive advantage, including technical search ability, learning ability, research and development ability, etc. For the country, independent innovation ability is based on society economic development of the objective requirements, consciously promote the scientific and technological knowledge of the production, mobility and application and in the process of creating wealth in order to achieve value-added ability. The ability of independent innovation is mainly a kind of 
system ability, not entirely a kind of technical ability, is an important part of national competitiveness but not equivalent to national competitiveness.

So, independent innovation is not only from the invention of the business process to the commercial process, but also a variety of institutions and organizations interact with the social process, which contains "technological innovation" also includes "non-technological innovation", including the concept of economics.

The Connotation of Low Carbon Economy. The so-called low-carbon economy, is under the guidance of the concept of sustainable development, through technological innovation, institutional innovation, industrial restructuring, new energy development and other means to minimize coal and other high-carbon energy consumption, reduce greenhouse gas emissions, To achieve economic and social development and ecological and environmental protection win-win situation of a form of economic development

\section{The Origin of Low - Carbon Independent Innovation}

Low-carbon economy is an economic model based on low energy consumption, low emissions, low pollution-based. In the proposed low-carbon economy process of less than ten years, low-carbon economy in the practice sector set off a giant storm and quickly swept the country. This is not deliberately hype and impractical, but because that the Earth's climate is indeed overwhelmed by excessive carbon emissions and has begun to vent their dissatisfaction to the people of the world and the human punishment. Climate change is the world's major environmental problems, penetrating into energy, food security, trade, finance and international security and many other areas, more and more attention by the international community. Low-carbon economy, as an effective way to deal with climate change and achieve sustainable development, has become the world's strategic choice to achieve greenhouse gas emission reduction targets to ensure sustained and healthy economic growth.

\section{Low Carbon Independent Innovation Background.}

Human society is gradually from the primitive society of agricultural civilization to modern industrial civilization with the biomass, wind, solar, water, fossil, nuclear energy development and utilization.

However, with the increase in the global population and the growing size of the economy, fossil fuels, bio-energy and other conventional energy use caused by environmental problems and their consequences continue to be known, in recent years, waste gas pollution, photochemical smog, water pollution And the effects of acid rain and the like, and the rise in atmospheric concentrations of carbon dioxide in the atmosphere will have been recognized as the serious consequences of human destruction of the natural environment, unhealthy lifestyles and the use of conventional energy. In this context, "carbon footprint", "low carbon economy", "low carbon technology", "low carbon development", "low carbon lifestyle", "low carbon society", "low carbon city", "low carbon World "and a series of new concepts, the new policy came into being. These concepts are proposed by governments and people hope that through the development of low-carbon economy towards ecological civilization, that is, to abandon the 20th century and the traditional growth model, the direct application of the new century innovation and innovation mechanism to achieve social sustainable development.

\section{The Origin and Development of Independent Innovation. .}

In economics, the concept of innovation originated in the "economic development theory" published by Schumpeter in 1912. The book argues that innovation refers to the introduction of a new combination of new factors of production and production conditions into the production system. It consists of five cases, namely: the introduction of a new product or the provision of a new product quality; the use of a new production method; to open up a new market; access to a raw material or semi-finished products of new sources of supply; Implement a new form of organization. He also specifically suggested that "innovation does not mean that the invention", an invention only applied to the field of economic activity and achieved success can be counted as "innovation." Schumpeter's innovative concept encompasses a wide range of innovations such as innovative and non-technical changes that involve technological change. In the 1960s, with the rapid development of the new technological revolution, Rostow proposed the "takeoff" six-stage theory, for the first time the concept 
of innovation for the development of technological innovation, technological innovation to innovation to the dominant position。

The clear definition of technological innovation is Enos in its "oil processing industry in the invention and innovation" in the first direct and clear, technical innovation is the result of several comprehensive behavior, including the invention of the choice, Capital investment assurance, organizational establishment, planning, recruitment of workers and opening up the market.

Since the 20th century, 70-8 years, the theoretical circles on the further study of innovation, began to form a systematic theory.Utterback in 1974 published "industrial innovation and technology diffusion" that, with the invention or technical samples of the distinction between innovation is the actual use of technology or the first application. Mueser systematically collated the concept of technological innovation in the mid-1980s, and suggested that technological innovation was a meaningful discontinuity event characterized by its novelty and success. Freeman from the perspective of economics to consider innovation, the object of innovation is basically defined as a standardized important innovation.

In the 1982 edition of Industrial Innovation Economics, he made it clear that technological innovation refers to the first commercial transformation of new products, new processes, new systems and new services.

\section{Origin and Development of Low Carbon Economy}

The term "low-carbon economy" was introduced at the beginning of the twentieth century, and it was only a solution to solve the energy problem. But "saving the world's energy and improving climate change" has been a global concern in the 1970s as the essential purpose of developing a low-carbon economy. In the international community, the origin of the low-carbon economy can be roughly divided into the following stages:

(1)limate change has aroused the concern of the international community

At the First World Climate Conference in 1979, climate change was on the agenda for the first time as a matter of concern to the international community. The United Nations established the Inter-governmental Panel on Climate Change (IPCC) in 1988 to monitor and report on global climate change. In 1987 United Nations Committee on Environment and Development Brantland's report "Our common future - from one earth to one world", opened the human re-evaluation of Western industrialization and its consequences, change the road to a more sustainable road

(2)The initial establishment of the global system of climate change to deal with the rules.

In June 1992, at the United Nations Conference on Environment and Development, more than 150 countries developed the United Nations Framework Convention on Climate Change with the aim of stabilizing greenhouse gas concentrations in the atmosphere at levels that do not pose a hazard to the climate system.

(3)Initiate a global action rule on climate change

In December 1997, at the Third Session of the United Nations Framework Convention on Climate Change, the participating countries adopted the Kyoto Protocol as a supplement to the United Nations Framework Convention on Climate Change (UNFCCC). The Kyoto Protocol sets out the idea of using market mechanisms to address environmental issues and sets out quantitative emission reduction targets for Annex I countries (developed countries and countries with economies in transition) of the Convention; that is, between 2008 and 2012, their greenhouse gas emissions An average reduction of 5.2 per cent at the 1990 level.

(4)Low-carbon economy formally put forward

The concept of "low-carbon economy" was proposed by British Prime Minister Tony Blair in a white paper entitled "Our Future Energy - Creating a Low Carbon Economy" on February 24, 2003, and the British government for low-carbon economic development Set a clear goal that Britain would cut its greenhouse gas emissions by 60 per cent by 1990 levels by 2050, fundamentally turning Britain into a low-carbon economy.

(5)Low carbon economy development period 
In October 2006, by the British government, the former World Bank chief economist Nicholas Stern led the "Stern report" that the global GDP 1\% per year investment, can avoid future GDP 5\% -20 \% Of the losses, calling for a global transition to a low-carbon economy. In December 2007, the United Nations Climate Change Conference in Bali, Indonesia, adopted the Bali Roadmap, requiring developed countries to reduce greenhouse gas emissions by 25 to 40 percent by 2020 . "Bali Roadmap" for the global further into the low-carbon economy has played a positive role, a milestone significance. In this context, the transformation of economic development model, from the traditional high-carbon economy to low energy consumption, low emissions, low pollution model transition is gradually being put on the agenda of the world. The G8 summit in 2009 suggested that by 2050 the total amount of greenhouse gas emissions in developed countries should be reduced by more than $80 \%$ on the basis of 1990 or a subsequent year, reducing global greenhouse gas emissions by at least $50 \%$ by 2050 . To achieve this goal, the global economy must transition to a low-carbon economy, which indicates that from now to 2050, low-carbon economy will be to enhance national competitiveness and organizational competitiveness of the inevitable choice.

\section{Independent Innovation is the Inevitable Choice to Meet the Challenge}

China's per capita energy resources in the world at a low level, but the energy consumption is in a gradual upward state. China's energy consumption increased by $11.9 \%$ in 2010, accounting for $20.3 \%$ of global energy consumption, catching up with the United States as the world's largest energy consumer.

In China's primary energy consumption structure, coal still occupy a substantial proportion, up to $70.45 \%$, while clean energy is only a small proportion $(6.72 \%$ of water and electricity, nuclear power accounted for $0.69 \%$, renewable energy accounted for $0.60 \%$ )(Fig. 1). This coal-based high-carbon energy structure not only poses a huge threat to the environment, but also restricts the transformation of China's economic development model.

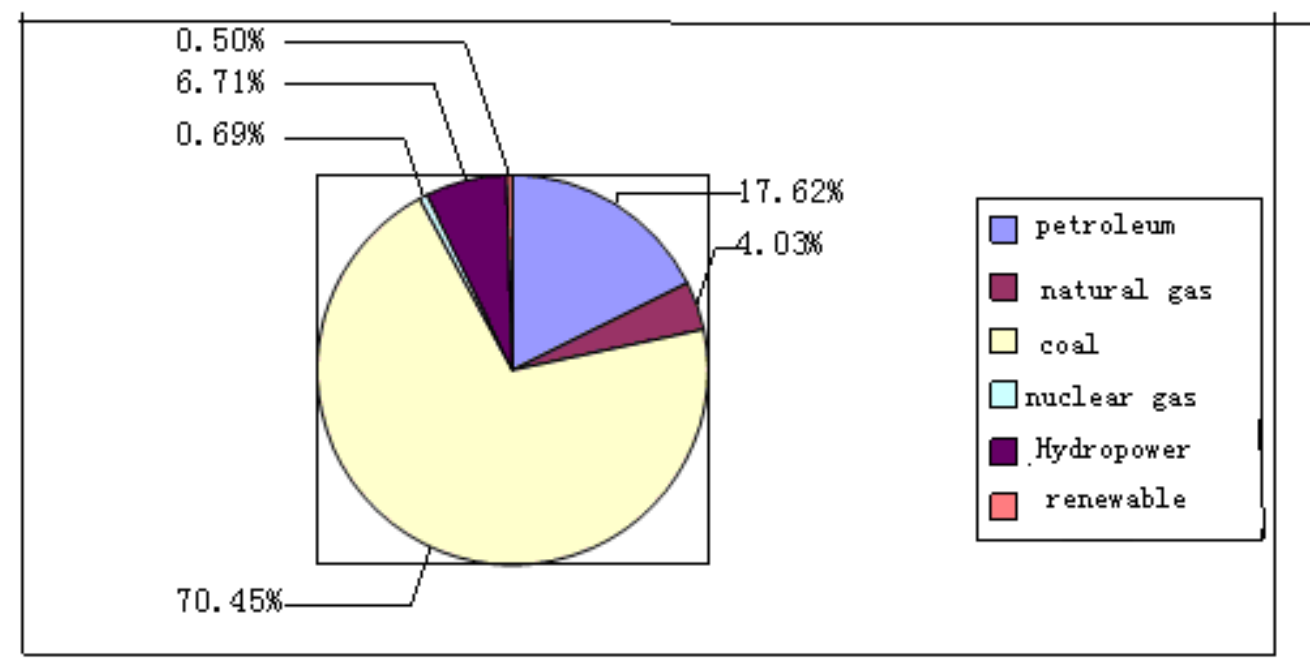

Figure 1. China 's Energy Structure in 2010

Typical carbon-based energy economic model, so that China's carbon dioxide emissions intensity is relatively high. According to the results of the study, the carbon dioxide emissions from primary energy consumption in China increased from 786.78 million tons in 1995 to 1469.19 million tons of carbon in 2006, with an average annual growth rate of 5.84\% and annual per capita carbon dioxide emissions from 0.62 tons Carbon / person increased to 1.12 tons of carbon / person in table 1. China's carbon dioxide emissions in 2007 has surpassed the United States ranks first in the world, of which the industrial sector of carbon dioxide emissions accounted for more than $84 \%$ of China's total carbon emissions. Therefore, China's energy-saving emission reduction situation is very grim, great pressure. 
Table 1 China 's carbon dioxide emission intensity changes

\begin{tabular}{|l|l|l|l|}
\hline & 1995 & 2006 & $\begin{array}{l}\text { Average annual } \\
\text { growth rate }\end{array}$ \\
\hline Carbon dioxide emissions & 78678 Million tons & $\begin{array}{l}146919 \text { Million } \\
\text { tons }\end{array}$ & $5.84 \%$ \\
\hline $\begin{array}{l}\text { Annual per capita carbon dioxide } \\
\text { emissions }\end{array}$ & $\begin{array}{l}0.62 \text { tons of carbon / } \\
\text { person }\end{array}$ & $\begin{array}{l}1.12 \text { tons of } \\
\text { carbon / person }\end{array}$ & $4.17 \%$ \\
\hline
\end{tabular}

Low carbon economy and independent innovation is the focus of the current theoretical circles, has gradually formed a multi-dimensional point of view and research conclusions. Through the combing of the connotation and type of low-carbon independent innovation, we can see that low-carbon independent innovation should be an all-round, three-dimensional and diversified innovation process. It is a multi-regional and multi- Space - time new innovation model. Therefore, to explore the era of low-carbon economy with Chinese characteristics of the new independent innovation model, to achieve economic growth to low carbon change.

\section{References}

[1] K Parikh. Sustainable development and low carbon growth strategy for India, J. Energy, Vol.40 (1994) No.1, 31-38.

[2] Furman, J.L., Porter, M.E., Stern, S. The determinants of national innovative capacity, J. Research Policy, 2002, 31(6):899-933. Vol.31 (2002) No.6, 899-933.

[3] UK Rout. Prospects of India's energy and emissions for a long time frame, J. Energy Policy, 2011, 39(9):5647-5663 Vol.39 (2011) No.9, 5647-5663.

[4] P Balachandra, D Ravindranath, NH Ravindranath. Energy efficiency in India: Assessing the policy regimes and their impacts [J]. Energy Policy, 2010, 38(11):6248-6438.

[5] Hu, X., Murgovski, N., Johannesson, L., Egardt, B. Energy efficiency analysis of a series plug-in hybrid electric bus with different energy management strate gies and battery sizes,J. Energy, Vol.111 (2013) No.11, 1001-1009.

[6] Ding, Y., Yang, H. Promoting energy-saving and environmentally friendlygeneration dispatching model in China: phase development and case studies, J. Energy Policy, Vol.57 (2013) No.6, $109-118$.

[7] Gao, C., Li, Y., Evolution of China's power dispatch principle and the newenergy saving power dispatch policy, J. Energy Policy, Vol.38 (2010) No.11, 17346-7357.

[8] Ji, S., Cherry, C.R., J., Bechle, M., Wu, Y., Marshall, J.D. Electric vehicles in China:emissions and health impacts, J. Environ. Sci. Technol, 2012, 46 (4), 2018-2024.

[9] Stern N. The Economics of Climate Change [M]. London: Cambridge University Press,2006.

[10] IPCC. Climate Change 2007: migitation. Contribution of Working Group III. To the Fourth Assessment Report of the Intergovernmental Panel on Climate Change[R]. London: Cambridge University Press. 2007. 